\title{
COMPETÊNCIAS COLETIVAS: CONSIDERAÇÕES ACERCA DE SUA FORMAÇÃO E DESENVOLVIMENTO
}

\author{
Francielle Molon da Silva * \\ franmolon@yahoo.com.br \\ Roberto Lima Ruas ** \\ roberuas@gmail.com
}

\begin{abstract}
*Universidade Federal de Pelotas - Pelotas, RS / Brasil
**Universidade Nove de Julho - São Paulo, SP/ Brasil
\end{abstract}

http://dx.doi.org/10.1590/1413-2311.0102015.54938

Recebido em 17/04/2015

Aprovado em 20/04/2016

Disponibilizado em 06/06/2016

Avaliado pelo sistema "double blind review"

Revista Eletrônica de Administração

Editora-chefe: Aurora Zen

ISSN 1413-2311 (versão "on line")

Editada pela Escola de Administração da Universidade Federal do Rio Grande do Sul.

Periodicidade: Quadrimestral

Sistema requerido: Adobe Acrobat Reader

\section{RESUMO}

Os processos e o desempenho das organizações são construídos por meio de ações coletivas as quais são especialmente resultantes da interação entre pessoas. Entretanto, as formas de gestão predominantes nas organizações permanecem orientadas pela atuação individual. Uma das dificuldades é a escassez de cultura e instrumentos teórico-empíricos para lidar com configurações coletivas. Assim, o objetivo deste trabalho é ampliar os conhecimentos acerca das configurações coletivas a partir da seleção de categorias de análise que viabilizem a identificação de elementos e dinâmicas que constituem os coletivos. Nesse sentido optamos por um estudo de caso desenvolvido no ambiente de Recursos Humanos, mais particularmente nas práticas de gestão de $\mathrm{RH}$ de uma empresa que atua no setor financeiro, a fim de construir conhecimentos sobre essa dimensão coletiva. A análise dos resultados revelou não apenas a presença de elementos capazes de configurar os coletivos de trabalho, mas também uma dinâmica de formação e desenvolvimento de competências coletivas, principais contribuições do artigo. O uso desse instrumental revelou a presença de duas competências coletivas dentre as práticas de $\mathrm{RH}$ examinadas: (a) relacionamento e colaboração e (b) capacidade de desenvolver soluções conjuntas, observando-se que a primeira foi avaliada em estágio mais avançado de consolidação. Finalmente, ainda como resultado deste estudo, foi elaborado um framework que sistematiza os resultados obtidos na perspectiva da formação e desenvolvimento de competências coletivas.

Palavras-chave: Trabalho Coletivo; Competências Coletivas; Gestão de Pessoas; Práticas de Gestão de Recursos Humanos. 


\title{
COLLECTIVE COMPETENCES AND THEIR CONTRIBUTION FOR UNDERSTANDING THE CONFIGURATION OF THE MANAGEMENT PRACTICES IN THE FIELD OF HUMAN RESOURCES MANAGEMENT
}

\begin{abstract}
Processes and the performance of organizations are built through collective actions arising especially from the interaction between people. However, the predominant forms of management in organizations remain driven by individual performance. One of the difficulties is the lack of theoretical and empirical settings to deal with collective knowledge. It is in this context that the concept of collective competence has been recognized. Thus, the objective of this work is to expand the knowledge of collective settings from the selection of categories of analysis that will allow the identification of elements and dynamics that constitute the collective. In this sense we chose a case study developed in the environment of Human Resources, more particularly in management practices HR company acting in the financial sector, in order to build knowledge on this collective dimension. The analysis of the results revealed not only the presence of elements capable of configuring the collective work, but also a dynamic training and competences development collective, main contributions of the article. The use of this instrument has revealed the presence of two collective competences among the practices of HR examined: relationship and collaboration and capacity to develop joint solutions, considering the first in more advanced stage of consolidation. Finally, also as a result of the work, a framework that represents the dynamics associated with the formation and development of collective competence was prepared.
\end{abstract}

Keywords: Collective Work; Collective Competences; Human Resource Management; Human Resources Management Practices.

\section{COMPETENCIAS COLECTIVAS Y SU CONTRIBUCIÓN A LA COMPRENSIÓN DE LAS PRÁCTICAS DE GESTIÓN E DE LA CONFIGURACIÓN EN EL CAMPO DE GESTIÓN DE PERSONAS}

\begin{abstract}
RESUMEN
Los procesos y el desempeño de las organizaciones se construyen a través de acciones colectivas que surgen especialmente de la interacción entre las personas. Sin embargo, las formas predominantes de la gestión en las organizaciones siguen estando impulsadas por el desempeño individual. Una de las dificultades es la falta de ajustes teóricos y empíricos para hacer frente a los conocimientos colectivos. Es en este contexto que el concepto de competencia colectiva ha sido reconocido. Por lo tanto, el objetivo de este trabajo es profundizar el conocimiento de valores colectivos desde la selección de las categorías de análisis que permitirá la identificación de los elementos y la dinámica que constituyen el colectivo. En este sentido hemos elegido un caso de estudio desarrollado en el entorno de los Recursos Humanos y, más en particular, en las prácticas de gestión de Recursos Humanos empresa del sector financiero, con el fin de construir conocimiento sobre esta dimensión colectiva. El análisis de los resultados revela no sólo la presencia de elementos capaces de configurar el trabajo colectivo, sino también un entrenamiento dinámico y el desarrollo de
\end{abstract}

REAd | Porto Alegre - Edição 83 - N 1 - Janeiro/Abril 2016 - p. 252-278 
capacidades colectivas, principales contribuciones del artículo. La utilización de este instrumento ha revelado la presencia de dos poderes colectivos entre las prácticas de recursos humanos: la relación y la colaboración y la capacidad para desarrollar soluciones conjuntas, teniendo en cuenta la primera en la etapa más avanzada de consolidación. Por último, también como resultado de la obra, se preparó un marco que representa la dinámica asociada con la formación y el desarrollo de la competencia colectiva.

Palabras clave: Trabajo Colectivo; Competencias Colectivas; Gestión de Personas; Prácticas de Gestión del Recursos Humanos.

\section{INTRODUÇÃO}

Os processos e o desempenho das organizações são construídos através de ações coletivas que são realizadas por pessoas e se consolidam através de relações de cooperação e interação. De fato, os resultados de uma organização dependem de conjuntos de atividades de natureza coletiva, atividades essas que podem ser realizadas tanto nos níveis operacionais, quanto nos estratégicos. (NELSON E WINTER, 1982). Entretanto, gestores e experts acadêmicos são conscientes da lacuna entre o discurso (que valoriza os desempenhos coletivos) e a realidade das organizações (cujos sistemas de gestão são geralmente centrados na atuação individual dos colaboradores).

Uma das evidências mais fortes acerca da orientação ao trabalho individual no contexto brasileiro de gestão de pessoas é a grande difusão da abordagem "competência individual" entre empresas privadas e instituições públicas, a partir do início do século XXI. (DIAS et al, 2008; MOLON DA SILVA, 2013). Mas não se trata de uma tendência observada unicamente em organizações brasileiras. Segundo pesquisa realizada entre empresas francesas, os profissionais e especialmente os gestores estão à busca, em geral de forma intuitiva, de outro modelo de performance, menos individual e mais próximo da atividade real, ou seja, mais próximo da configuração coletiva. (LE BOULAIRE et al , 2013).

No ambiente acadêmico, a relação entre coletivos e desempenho tem sido objeto de debates teóricos, de cunho mais abstrato. Uma teoria que trata deste tema é a denominada Visão Baseada em Recursos (VBR). A VBR é sustentada na tese de que os processos de seleção e gestão de recursos internos são fundamentais no desempenho competitivo das organizações e constitui uma das correntes mais importantes nos estudos e debates sobre gestão estratégica, mesmo nos dias de hoje. Miranda et. al. (2015), por exemplo, apontam que a seleção e a gestão de recursos internos é uma das principais alternativas para promover 


\section{COMPETÊNCIAS COLETIVAS: CONSIDERAÇÕES ACERCA DE SUA FORMAÇÃO E DESENVOLVIMENTO}

capacidade inovativa e, portanto, conseguir diferenciação competitiva no ambiente econômico contemporâneo.

Segundo trabalhos que fundamentam essa corrente, as pessoas aparecem com destaque dentre os recursos mais relevantes para as organizações, em função de seus conhecimentos, habilidades e expertises. (WERNERFELT, 1984; BARNEY, 1991). Por outro lado, outros estudos desta mesma corrente destacam particularmente o importante papel dos coletivos de pessoas na construção do desempenho e da competitividade nas organizações. Dentre esses, um dos mais destacados, até mesmo por ser qualificado como um dos trabalhos precursores da VBR, seus autores, Nelson e Winter (1982), desenvolvem o conceito de Rotinas Organizacionais (RO), conceito ainda hoje reconhecido como dos mais importantes desta corrente. (FELDMAN, 2000; BECKER, 2003; 2005; 2008; PENTLAND; FELDMAN, 2005; PARMIGIANI;HOWARD-GRENVILLE,2011; FELIN et al., 2012). Segundo os autores seminais, as RO seriam padrões coletivos de ações organizacionais interdependentes, ordenadas em função de objetivos previamente definidos e que por isso seriam centrais para o desempenho e a competitividade da organização. (NELSON; WINTER, 1982).

Outros trabalhos importantes associados à VBR também destacam o papel dos coletivos no desempenho organizacional, como, por exemplo, o de Grant (1991), no qual o autor defende que a consecução de objetivos organizacionais passa pela cooperação e coordenação de trabalhos individuais a fim de construir atividades coletivas. Stalk et al (1992), por sua vez, tratam a dinâmica da prática coletiva como um fator de diferenciação: é a capacidade de gerir um conjunto de processos e práticas de negócios que fornecem valor ao cliente; já o conceito de core competence tem na sua base a configuração coletiva a fim de atingir objetivos competitivos (PRAHALAD e HAMEL, 1990).

Mais adiante, ainda no desdobramento da VBR, nos estudos sobre Competências Organizacionais, Sanchez e Heene (2004) entendem que a noção de competências se configura através da interação entre pessoas e grupos, de dentro e de fora da empresa, bem como da interação entre fornecedores, clientes e empresas. Essa visão que confirma as competências organizacionais como dimensão coletiva, mas assentada em processos de interação e cooperação entre pessoas, é também compartilhada com Mills et. al (2002), King, Fowler e Zeithalm (2002), Helfat e Peteraf (2003), Ljungquist (2007) e Warnier (2008).

Essa breve revisão de trabalhos associados à teoria VBR revela que são muitos os argumentos destacando a relação entre a dimensão coletiva do trabalho humano no processo de construção do desempenho das organizações. Entretanto, apesar de evidências empíricas da

REAd | Porto Alegre - Edição 83 - N 1 - Janeiro/Abril 2016 - p. 252-278 


\section{Francielle Molon da Silva \& Roberto Lima Ruas}

expansão das configurações coletivas no ambiente organizacional (DEFELIX et al., 2014), a cultura gerencial e os respectivos instrumentos de gestão nas organizações não estão apropriando essas mudanças, nem tampouco os estudos empíricos sobre gestão de pessoas. De fato, continuam raros os trabalhos, teóricos ou empíricos, que se dispõem a tratar da gestão de coletivos, como uma forma complementar ou alternativa para repensar as configurações do trabalho nas organizações.

Foi nesse cenário que o conceito de competência coletiva (CC) passou a ser valorizado, justamente por sua proximidade com a gestão de pessoas e com a dimensão coletiva do trabalho, sem perder de vista a perspectiva estratégica. (RETOUR et al, 2011). Por outro lado, o debate sobre CC tem dedicado mais atenção à construção teórica, recorrendo a diferentes abordagens teóricas tais como (i) a noção de rotinas organizacionais em Nelson e Winter (1982) e Grant (1991), (ii) os processos de aprendizagem social via interação de conhecimentos e habilidades individuais em Sandberg (1996), (iii) a socialização e cooperação no trabalho em Zarifian (2001); por outro, a compreensão da dinâmica das CC tem sido sustentada em trabalhos empíricos associados à gestão estratégica de pessoas. (RETOUR; KROHMER, 2006; MICHAUX, 2011; COLIN; GRASSER, 2011; PAUVERS; SCHIEB-BIENFAIT, 2011).

Em função desses fundamentos, a questão das CC no ambiente organizacional passou a constituir uma referência para os autores deste artigo investigarem a dimensão coletiva, pois é nessa configuração que se desenvolvem as CC. Entendemos configurações ou dimensões coletivas como as configurações de trabalho nas quais a atuação coletiva se sobrepõe a individual, ou seja, o trabalho individual deve seguir as determinações do coletivo.

A pesquisa é desenvolvida no campo da Gestão de Recursos Humanos (GRH), área responsável pelas funções de seleção, organização, acompanhamento, avaliação, desenvolvimento e outras funções associadas à relação salarial das pessoas da organização, considerando a concepção da VBR que entende que as pessoas são recursos valiosos, raros e inimitáveis. Diferenciamos, portanto, a GRH da Gestão de Pessoas, cujas atividades compreendem a gestão do trabalho em toda a organização, função que é compartilhada pelos gestores de todas as áreas da organização.

Uma outra referência importante neste trabalho são as práticas de Gestão de Recursos Humanos, entendidas aqui como a manifestação concreta de políticas e princípios de gestão de pessoas, na forma de hábitos, rotinas e ações associadas a área em questão. (MASCARENHAS, 2008). 


\section{COMPETÊNCIAS COLETIVAS: CONSIDERAÇÕES ACERCA DE SUA FORMAÇÃO E DESENVOLVIMENTO}

Assim, o objetivo deste estudo é levantar e analisar práticas de Gestão de Recursos Humanos embasadas nas configurações coletivas, as quais possam contribuir para a formação e desenvolvimento de competências coletivas. As etapas de revisão bibliográfica, da pesquisa de campo, bem como a análise das informações levantadas auxiliaram na definição e ordenação dos papéis e articulações entre os elementos teórico-empíricos da pesquisa, a saber: competências coletivas, práticas de Gestão de Recursos Humanos e configurações coletivas.

O campo empírico de investigação é o da gestão estratégica de pessoas numa organização voltada a serviços financeiros e cuja constituição societária tem a forma de uma cooperativa de crédito. O método de pesquisa adotado na investigação foi qualitativo, pautando-se pela realização de um estudo de caso, em que foram consideradas como principais técnicas de coleta de dados a análise de documentos e as entrevistas semiestruturadas com gestores que atuavam na área investigada.

Os principais resultados mostram que certas práticas de gestão de recursos humanos são capazes de gerar e desenvolver competências do tipo coletiva se estiverem ligadas ao estímulo dos processos de interação, compartilhamento e cooperação no trabalho. As evidências de competências coletivas (CC), por sua vez, foram monitoradas por meio do uso da noção de atributos de $\mathrm{CC}$, noção recuperada da teoria. Os atributos de CC podem ser definidos como qualidades de um determinado coletivo de trabalhadores/profissionais, que resultam da recorrência e continuidade da atuação coletiva, como por exemplo, a memória de problemas ou situações anteriores que é compartilhada por membros desse coletivo. (RETOUR; KROHMER, 2011).

Para tanto, este artigo está estruturado da seguinte maneira: revisão da literatura, procedimentos metodológicos; apresentação e discussão dos principais resultados encontrados; e as considerações finais, apontando contribuições do estudo e caminhos de pesquisas futuras.

\section{COMPETÊNCIAS COLETIVAS}

Apesar da importância que a literatura associada à VBR atribui à articulação entre dimensão coletiva do trabalho e desempenho e competividade das organizações, essa relevância não tem sido compartilhada no ambiente organizacional. Nesse ambiente, a configuração coletiva não assume papel relevante na gestão estratégica de pessoas, cujos sistemas e práticas são, sobretudo, focados na orientação, na avaliação e no desenvolvimento 


\section{Francielle Molon da Silva \& Roberto Lima Ruas}

da atuação individual. Um exemplo dessa condição é revelado por Comini e Fernandes (2008) em pesquisa acerca da difusão do modelo competências no ambiente organizacional: os autores constatam uma grande frequência de casos cujo modelo é fundamentado em competências individuais, contra uma frequência praticamente nula de casos valorizando a dimensão coletiva em seus sistemas de gestão de pessoas. Provavelmente, a escassez de experiências empíricas, assim como a ausência de procedimentos e instrumentos capazes de auxiliar na operacionalização da concepção coletiva, é o que tem afastado as organizações dessa alternativa.

Essa situação, conforme observamos acima, é muito diferente quando se trata do debate teórico. Em Nelson e Winter (1982), já citado anteriormente, são as práticas coletivas de trabalho, na forma de Rotinas Organizacionais, o que define as condições de competição da organização. Segundo essa abordagem, são exigências do ambiente as principais causas para mudanças nas práticas coletivas e por extensão nas rotinas organizacionais. Entendemos que mesmo sem empregar diretamente a noção de competências coletivas, os autores tratam de um conceito similar: capacidades coletivas necessárias à mudança.

A noção de competência coletiva está também presente em trabalhos como os de Javidan (1998); Mills et. al. (2002); Sanchez e Heene (2004), os quais, ao tratar do papel das competências organizacionais na estratégia das organizações, destacam também a presença de uma dimensão intermediária de competências, posicionadas entre as competências estratégicas e as competências individuais, o que certamente posiciona essas figuras como dimensões coletivas de competências.

Uma contribuição importante para a construção do conceito de competências coletivas tem origem no trabalho de Heene e Sanchez (1997), os autores que entendem que as competências da organização são sistêmicas, holísticas e cognitivas e precisam equilibrar duas realidades distintas: a dinâmica e a complexidade do mundo real e as capacidades cognitivas do homem frente a essa complexidade.

O debate acerca da gestão por competências no Brasil avançou por trajetória semelhante ao apresentar uma dinâmica intermediária de competências, situada entre as individuais e as organizacionais, denominadas competências funcionais ou intermediárias, cuja natureza é também funcional. (RUAS, 2001; BRANDÃO; GUIMARÃES, 2001; BITENCOURT, 2004).

A dimensão coletiva estaria também presente entre alguns dos principais trabalhos acerca da abordagem competências na dimensão individual, especialmente em sua perspectiva relacional, a partir da valorização de processos de cooperação, interação e compartilhamento 


\section{COMPETÊNCIAS COLETIVAS: CONSIDERAÇÕES ACERCA DE SUA FORMAÇÃO E DESENVOLVIMENTO}

do trabalho individual. Le Boterf (2002) considera a importância da dimensão coletiva das competências, mas ressalva que essa missão não é simples, já que ela representa mais que a soma das competências individuais. Propõe então a abertura para a cooperação como requisito da atuação profissional. Entretanto, embora pretenda tratar de dimensão coletiva, continua a tratar de um tipo de atuação individual baseada na cooperação e relacionamento no trabalho.

Hansson (2003) também parte das competências individuais para pensar as coletivas. Segundo o autor, a competência coletiva é formada por dois elementos da competência individual: a competência prática (ligada à execução das tarefas); e a interpessoal (interação social para realizar as atividades). Entretanto, em seu conceito sobre competência coletiva, embora genérico, produz algum avanço: a capacidade de um grupo de pessoas para realizar atividades de uma maneira coletiva, atividades essas que não poderiam ser realizadas de maneira individual.

Em Zarifian (2001) o conceito de competência coletiva também começa pelos indivíduos cuja sinergia pode provocar interações sociais ativadas no interior de um grupo, gerando uma dinâmica coletiva importante para a organização. Também Frohm (2002) ocupa um espaço intermediário entre indivíduo e coletivo ao afirmar que a competência coletiva acontece de acordo com duas lógicas: interativa e interrelacional. A lógica interativa tem a ver com um fenômeno coletivo de troca de experiências, e a lógica interrelacional, por sua vez, compreende as experiências pessoais compartilhadas e aquelas que foram discutidas em grupo. Aliás, essa dinâmica social ocupando um espaço intermediário entre indivíduo e coletivo aparece em nosso entendimento como a porta de entrada para a noção de competência coletiva.

Outra contribuição importante na construção da dimensão coletiva tem origem nos trabalhos de Sandberg (1996) e de Sandberg e Targama (2006). Os autores introduzem um novo elemento: a compreensão que as pessoas atuando num mesmo contexto precisam ter sobre suas atribuições. Ou seja, o conhecimento do que precisa ser feito pode dar sentido às atividades e tornar-se fator de estímulo para se alcançar um resultado adequado. É nessa perspectiva que a socialização do trabalho, especialmente aquela que ocorre via compartilhamento de sentido, viabiliza o entendimento das atividades numa dimensão coletiva. Sandberg e Tagarma (2006) qualificam os processos de interação, compartilhamento e cooperação entre os indivíduos, grupos ou atores sociais que integram uma organização, como a dimensão social das competências coletivas.

REAd | Porto Alegre - Edição 83 - N 1 - Janeiro/Abril 2016 - p. 252-278 


\section{Francielle Molon da Silva \& Roberto Lima Ruas}

O que se observa dessas importantes contribuições para a compreensão da noção e dinâmica das competências organizacionais é que elas são fundamentadas na atuação de indivíduos, mas valorizando sua perspectiva relacional. Por isso compõem o que Sandberg e Tagarma (2006) denominam dimensão social das competências coletivas. Retour e Krohmer (2006) seguem também essa linha, ao afirmar que as competências coletivas são resultantes do desenvolvimento de competências individuais. Mas os autores introduzem também uma perspectiva organizacional ao defender que as competências coletivas são também elementos constitutivos das competências-estratégicas da organização.

Essa dupla perspectiva, social e organizacional, tem papel importante nos trabalhos de Michaux (2005; 2011). Nesses trabalhos a autora posiciona as CC como o resultado da mobilização de duas dinâmicas simultâneas: os processos de interação e compartilhamento entre indivíduos e grupos (a base social das competências coletivas) e os processos de direcionamento e gestão dos coletivos (que é a base funcional das CC, a qual é sustentada no conceito de Rotinas Organizacionais).

Em sua dimensão social, a competência coletiva se refere à interação entre competências de um conjunto de indivíduos, grupos ou atores sociais que integram uma organização. Considera como aspectos sociais da noção de competências coletivas: (i) a sinergia e o entendimento comum das regras coletivas de relacionamento (o que permite que indivíduos trabalhem juntos na equipe); (ii) a aprendizagem coletiva sob a forma de aprendizagem voltada à criação de um novo saber, o que pode resultar em inovação; (iii) o compartilhamento de saberes e expectativas (reflexão coletiva, conduzida pela lógica de melhoria e pela experiência, sendo que esse compartilhamento pode ser explícito ou não, e, finalmente), (iv) a cooperação e a comunicação (ligada à rede informal de cooperação e gestão). (MICHAUX, 2011).

Já na perspectiva funcional, a competência coletiva é vista como um conjunto de recursos que complementam ou reforçam as competências organizacionais, representando os diferentes setores ou principais funções coletivas da organização, sendo correspondentes a atribuições específicas de grupos ou processos (NORDHAUG e GRÖNHAUG, 1994; MICHAUX, 2011).

Contribuições considerando as competências coletivas como um tipo específico de competências estão também presentes nos trabalhos de Dejoux (1998), Dubois e Retour (1999) e Bataille (2001). Na produção brasileira sobre o tema, os trabalhos de Rosa e

Bitencourt (2010), Bonoto e Klein (2010), Bonotto e Bitencourt (2006) compartilham a tese

REAd | Porto Alegre - Edição 83 - N 1 - Janeiro/Abril 2016 - p. 252-278 


\section{COMPETÊNCIAS COLETIVAS: CONSIDERAÇÕES ACERCA DE SUA FORMAÇÃO E DESENVOLVIMENTO}

de que as competências coletivas podem ser compreendidas e analisadas através de suas naturezas funcional e social.

Ainda cabe destacar pesquisas que contribuem para o entendimento da dinâmica e configuração de competências coletivas. Pauvers e Schieb-Bienfait (2011), por exemplo, relatam uma experiência na qual a organização adota princípios e práticas de gestão de RH que acabam por estimular a construção de competências coletivas estratégicas. Dentre esses princípios e práticas, destaque para o incentivo às relações informais em todos os níveis, à institucionalização da participação e democratização das decisões, ao compartilhamento da aprendizagem, à autonomia e iniciativa na gestão do trabalho. Os resultados desse trabalho revelam que, em certos casos, determinadas políticas, princípios e práticas de gestão podem constituir importantes facilitadores na construção de competências coletivas.

Em outro estudo de base empírica sobre competências coletivas, Retour e Krohmer (2011) observam que a interação entre competências individuais, no contexto equipes, resulta na formação de competências coletivas intragrupos, as quais, segundo os autores são competências fundamentais para o desempenho da organização. Observa-se que o saber-fazer operacional, próprio de um grupo, pode lhe oportunizar, no passar do tempo, um desempenho superior. Ao mesmo tempo, as pessoas, através das interações e processos de troca no grupo, acabam por compor um modo de agir único que é associado à atuação do grupo. Ou seja, quando se separam e voltam a desenvolver seus trabalhos individualmente, realizam-no como se o fosse em conjunto, isso porque existem alguns atributos que balizam essas ações. (RETOUR; KROHMER, 2011).

Essas observações conduzem os autores a identificar quatro atributos que resultam da perspectiva social das competências coletivas: os referenciais comuns que agilizam a comunicação entre as pessoas da equipe; a linguagem compartilhada diz respeito a um vocabulário comum utilizado no trabalho, incluindo gestos, olhares, silêncios, etc.; a memória

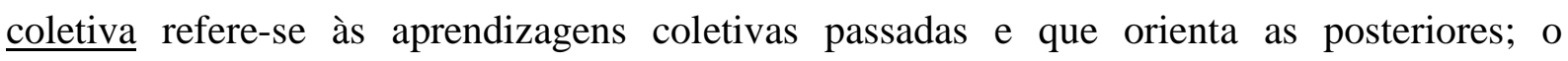
engajamento subjetivo que representa a mobilização das pessoas para os objetivos da empresa como um todo. (RETOUR; KROHMER, 2011). Esses atributos vão desempenhar um papel importante nas observações e análises que compõem nossa pesquisa.

Ainda repercutindo a produção brasileira neste campo, cabe destacar a revisão conceitual sobre competências coletivas em Molon da Silva (2012), a partir da qual a autora identifica elementos associados às competências coletivas, os quais são reproduzidos no Quadro 1 seguir.

REAd | Porto Alegre - Edição 83 - N 1 - Janeiro/Abril 2016 - p. 252-278 


\section{Francielle Molon da Silva \& Roberto Lima Ruas}

Quadro 1- Referências associadas à identificação de competências coletivas

\begin{tabular}{|c|c|}
\hline Autor & Referências Teóricas associadas à identificação das competências coletivas \\
\hline $\begin{array}{l}\text { Nelson e Winter } \\
\quad(1982)\end{array}$ & $\begin{array}{l}\text { As práticas coletivas de trabalho seriam as práticas nas quais se desenvolvem as } \\
\text { principais rotinas de trabalho da organização e é nelas que os trabalhos individuais } \\
\text { são integrados e estabilizados numa configuração coletiva. }\end{array}$ \\
\hline Sandberg (1996) & $\begin{array}{l}\text { Socialização e Interação: Resultado da interação entre as competências individuais } \\
\text { com base no sentido compartilhado pelos membros do grupo e nos processos de } \\
\text { interação do trabalho }\end{array}$ \\
\hline Zarifian (2001) & $\begin{array}{l}\text { O conceito de competência coletiva também começa pelos indivíduos cuja sinergia } \\
\text { pode provocar interações sociais ativadas no interior de um grupo, gerando uma } \\
\text { dinâmica coletiva importante para a organização }\end{array}$ \\
\hline \multirow[b]{2}{*}{ Frohm (2002) } & Lógica interativa: Fenômeno coletivo de troca de experiências \\
\hline & $\begin{array}{l}\text { Lógica interrelacional: Experiências pessoais e com aquelas que foram discutidas } \\
\text { em grupo }\end{array}$ \\
\hline Hansson (2003) & $\begin{array}{l}\text { Construção de significados coletivos e ação intencional ou reflexiva a partir de uma } \\
\text { ação interativa baseada em habilidades. }\end{array}$ \\
\hline \multirow{3}{*}{ Michaux (2005) } & $\begin{array}{l}\text { Dinâmica dentro da equipe: Regras de relacionamento que fazem com que } \\
\text { trabalhem juntos }\end{array}$ \\
\hline & $\begin{array}{l}\text { Aprendizagem coletiva: Mudança da aprendizagem para a criação de um novo } \\
\text { saber. Resultado da aprendizagem organizacional ou coletiva a partir da introdução } \\
\text { de alguma inovação. }\end{array}$ \\
\hline & $\begin{array}{l}\text { Compartilhamento de saberes e expectativas: Reflexão coletiva, explícita ou não. } \\
\text { Ligado à Tecnologia da Informação e Comunicação. } \\
\text { Cooperação e comunicação: Rede informal de comunicação. }\end{array}$ \\
\hline $\begin{array}{l}\text { Retour e Krohmer } \\
(2006)\end{array}$ & $\begin{array}{l}\text { Atributos de Competências Coletivas: } \\
\text { compartilhada, Memória coletiva e Envolvimento subjetivo. }\end{array}$ \\
\hline \multirow{6}{*}{$\begin{array}{l}\text { Pauvers e Schieb- } \\
\text { Bienfait (2009) }\end{array}$} & Fatores individuais \\
\hline & Gestão de Recursos Humanos \\
\hline & Processos organizacionais \\
\hline & Estrutura \\
\hline & Identidade \\
\hline & Valores \\
\hline
\end{tabular}

Fonte: Molon da Silva, 2012.

Enfim, nesta etapa do trabalho cabe identificar os recursos teóricos selecionados como elementos de referência para análise das evidências da dimensão coletiva: os conceitos de práticas coletivas, na perspectiva de Rotinas Organizacionais (NELSON e WINTER, 1982; MICHAUX, 2011); as diferentes formas de compartilhamento, cooperação, interação e socialização do trabalho e das expectativas individuais (SANDBERG, 1996; ZARIFIAN, 2001; FROHM; 2002; HANSSON, 2003); as políticas de gestão capazes de mobilizar a cooperação e a interação dos trabalhos individuais (PAUVERS; SCHIEB-BIENFAIT, 2011); e os atributos de competências coletivas (RETOUR; KROHMER, 2011)

Consideramos também nessa seleção, os resultados de pesquisa realizada entre empresas atuando no Brasil, na qual os autores investigam configurações coletivas presentes em processos organizacionais e acabam por identificar e justificar quatro elementos centrais na formação da dimensão coletiva do trabalho: processos de compartilhamento e interação do 


\section{COMPETÊNCIAS COLETIVAS: CONSIDERAÇÕES ACERCA DE SUA FORMAÇÃO E DESENVOLVIMENTO}

trabalho individual, práticas coletivas de trabalho, políticas de gestão que mobilizam a socialização do trabalho e atributos de competências coletivas. (RUAS et al., 2013)

\section{PROCEDIMENTOS METODOLÓGICOS}

A pesquisa que sustenta este artigo caracteriza-se como de natureza qualitativa sob o enfoque de estudo de caso, tendo como principais fontes de coleta de dados entrevistas semiestruturadas e análise documental, os quais foram submetidos à análise de conteúdo. A escolha de uma abordagem qualitativa se deve a possibilidade de realizar: (a) uma análise situada (em cenários, contextos, espaços determinados) e holística, em que o pesquisador interpreta e dá sentido a elementos da realidade; (b) uma análise interpretativa (criando significados), na qual a linguagem é uma ferramenta fundamental para reconstruir, dando vida ao que se relata (GOETZ e LECOMPTE, 1988). O trabalho assume a estratégia de estudo de caso porque de acordo com as proposições do Yin (2001, p. 32): "um estudo de caso é uma investigação empírica que investiga um fenômeno contemporâneo dentro de seu contexto da vida real, especialmente quando os limites entre o fenômeno e o contexto não estão claramente definidos".

O objeto da investigação foi o ambiente e a atuação da área de gestão de pessoas de uma empresa cuja atividade é voltada a serviços financeiros, presente em vários estados do sul do Brasil, mas especialmente no Rio Grande do Sul. O pressuposto da pesquisa remete à questão que introduz esse artigo - a lacuna entre o discurso (que valoriza a dimensão coletiva como fundamental para o desempenho organizacional) e a realidade das organizações (cujos sistemas de gestão é centrado na atuação dos indivíduos). Considerado o escasso número de trabalhos empíricos tratando da dimensão coletiva, nossa pretensão foi a de identificar elementos que pudessem evidenciar a presença dessa configuração coletiva na empresa investigada. Essa descoberta, entendemos nós, pode contribuir no debate sobre a natureza da dimensão coletiva e sobre formas de promover sua gestão.

Nesse sentido, o trabalho de Pauvers e Schieb-Bienfait (2011) representou um grande incentivo para a escolha da área de gestão de pessoas como objeto- ambiente onde a pesquisa é desenvolvida, a medida em que os resultados dessas autoras revelam que a área da gestão de pessoas pode incentivar interações coletivas e o compartilhamento de identidades, valores e cultura e dessa forma, mobilizar a formação da dimensão coletiva e, por extensão, de competências coletivas. Certamente, esse tipo de mudança implica na adoção de novos papéis 


\section{Francielle Molon da Silva \& Roberto Lima Ruas}

na Gestão de Pessoas, tais como os descritos em Nunes e Oliveira (2010), refletindo mudanças estruturais e estratégicas das organizações.

Já a decisão de escolher as práticas de gestão de recursos humanos como tema central na definição das competências coletivas se deve especialmente à revisão de literatura. Em primeiro lugar, observamos no debate acima que as práticas coletivas constituem o locus sobre o qual se constituem configurações do trabalho coletivo. (NELSON e WINTER, 1982). Por sua vez, o uso da expressão "práticas de gestão de recursos humanos" se refere à práticas coletivas capazes de tornar tangível os princípios e políticas desta área, segundo Demo e Nunes (2012). Concepção semelhante é compartilhada por Ulrich e Beatty (2001); Mascarenhas (2008); e Grimand (2011). Por fim, é a recorrência de atividades/práticas de natureza coletiva que vão viabilizar a constituição de CC.

A coleta de dados foi realizada através de análise documental e de uma série de entrevistas semiestruturadas com profissionais da empresa investigada. A análise documental compreendeu relatórios avaliativos e projetos da organização, incluindo documentos confidenciais. Também recorremos ao site da empresa, em busca de uma outra fonte primária de informações. As entrevistas semiestruturadas foram realizadas mediante a utilização de um roteiro com questões abertas, que norteou a discussão durante todo o desenvolvimento do trabalho. Segundo Triviños (1987, p. 174), a "entrevista semiestruturada é aquela que utiliza questionamentos básicos, apoiados em teorias e hipóteses, que interessam à pesquisa e que, em seguida, oferecem amplo campo de interrogações, ao lado de novas hipóteses que vão surgindo à medida que o pesquisador recebe as respostas do informante.”.

As entrevistas foram aplicadas ao longo do trabalho, seguindo as fases propostas anteriormente, junto a pessoas da área de Gestão de Pessoas da organização. O número de entrevistas realizadas foi de 24 , incluindo as duas entrevistas piloto. Uma dessas duas foi usada como base de análise dos resultados, pois além de contribuir com a análise do conteúdo das perguntas e com a visão dos autores acerca da compreensão das questões pelos entrevistados, foi possível avaliar também o tempo médio necessário para cada entrevista e prevenir problemas eventuais que poderiam surgir em questões específicas. As entrevistas foram realizadas com colaboradores de 3 sub-áreas e as entrevistas foram encerradas quando as respostas começaram a apresentar repetições. As entrevistas duraram em média $1 \mathrm{~h}$, sendo que o tempo mínimo foi de 45 minutos e o máximo de 1 h e 30 min. O contato prévio com os entrevistados ocorreu por intermédio de um dos colaboradores da Gestão de Pessoas a qual realizavam o primeiro contato e intermediavam o recebimento de uma carta de apresentação do projeto. No momento inicial das entrevistas, após a breve contextualização da pesquisa, os

REAd | Porto Alegre - Edição 83 - Nº 1 - Janeiro/Abril 2016 - p. 252-278 


\section{COMPETÊNCIAS COLETIVAS: CONSIDERAÇÕES ACERCA DE SUA FORMAÇÃO E DESENVOLVIMENTO}

participantes assinavam um termo de consentimento, autorizando a gravação e utilização de seus conteúdos sem identificação.

As entrevistas foram transcritas e houve uma triangulação dos dados utilizando a análise de conteúdo, a qual é considerada um procedimento de pesquisa que se situa em um delineamento mais amplo da teoria da comunicação e tem como ponto de partida a mensagem, permitindo ao pesquisador fazer inferências sobre qualquer um dos elementos de comunicação (FRANCO, 2005). Para Bardin (2002), a análise de conteúdo pode ser considerada como um conjunto de técnicas de análises de comunicações que utiliza procedimentos sistemáticos e objetivos de descrição do conteúdo das mensagens, cuja intenção é realizar a inferência de conhecimentos relativos às condições de sua produção e recepção, "inferência esta que recorre a indicadores (quantitativos ou não) (BARDIN, 2002, p. 38)".

$\mathrm{Na}$ etapa de análise, foi realizado um estudo detalhado do conteúdo do material investigado (documentos, registros e meios de divulgação) e das entrevistas semiestruturadas, procurando captar o sentido das frases e das palavras utilizadas. Em seguida foram comparadas e avaliadas estas entrevistas, descartando o que não se entendeu como muito significativo. Finalmente, reconhecer o essencial e selecioná-lo em torno das principais ideias (LAVILLE E DIONNE, 1999). Para fins de identificação dos entrevistados, foi utilizada a letra "E" seguida de um número aleatório (E1, E13, por exemplo), que não tem nenhuma relação com a sequência da realização das entrevistas, no intuito de manter o sigilo dos sujeitos. A classificação dos dados foi realizado com o auxílio do software de análise qualitativa NVivo (Qualitative Data Analisys Software). Todas as entrevistas foram transcritas e armazenadas no software, bem como os documentos digitalizados que foram disponibilizados pela organização.

A concepção preliminar das categorias de análise empregadas para verificar evidências de elementos associados à dimensão coletiva e às competências coletivas teve origem na revisão teórica, incluindo pesquisas empíricas conforme relato anterior. Entretanto a consolidação dessas categorias ocorreu de fato durante a análise e reflexão dos resultados em todas as etapas finais da pesquisa. Essas categorias de análise são duas: (i) elementos mobilizadores para a formação e desenvolvimento de competências coletivas (como dimensão coletiva), considerando as políticas de gestão que estimulam processos de interação, compartilhamento e socialização do trabalho e as práticas de GRH capazes de operacionalizar os princípios e políticas voltadas a "socialização" do trabalho gerando configurações 


\section{Francielle Molon da Silva \& Roberto Lima Ruas}

coletivas; e (ii) identificação das competências coletivas da área de gestão de pessoas, a partir dos atributos de competências coletivas, resultantes da recorrência de atividades de modo coletivo e que acabam por formar e desenvolver competências coletivas.

A definição e a validação dessas categorias são resultantes de diversas consultas e análises minuciosas a partir da triangulação dos dados.

\section{APRESENTAÇÃO E ANÁLISE DOS DADOS}

A análise das informações levantadas na pesquisa é desenvolvida em duas subseções: a primeira trata de elementos capazes de mobilizar uma configuração coletiva no contexto de trabalho da organização investigada e a segunda, da identificação de competências coletivas neste mesmo espaço organizacional.

\subsection{Elementos Mobilizadores da Configuração Coletiva}

Conforme observamos na revisão teórica, as práticas de gestão de pessoas se concretizam por meio de hábitos, rotinas e ações associadas à área de gestão de pessoas. Por outro lado, essas práticas são a manifestação concreta de grande parte dos princípios, políticas e diretrizes de gestão de pessoas de uma organização. (MASCARENHAS, 2008). Evidentemente, essas práticas são também influenciadas, no mundo organizacional, pelas condições específicas da cultura, da atuação gerencial, do clima interno da organização, além de outros elementos associados à natureza humana, como identidade, valores e busca de satisfação. (PAUVERS; SCHIEB-BIENFAIT, 2009).

$\mathrm{O}$ primeiro eixo deste tópico da análise buscou identificar as práticas de gestão RH $(\mathrm{GRH})$, presentes nas operações da empresa investigada, que apresentassem potencial de mobilizar o trabalho individual e de formarem configurações coletivas. A análise das informações levantadas em diversas fontes de coleta orientou a construção do quadro 2, no qual apresentamos uma síntese das informações relevantes para a definição das práticas de gestão RH, bem como das principais funções que desempenham, considerando as contribuições de Pauvers e Schieb-Bienfait (2011) e Demo e Nunes (2012). 


\section{COMPETÊNCIAS COLETIVAS: CONSIDERAÇÕES ACERCA DE SUA FORMAÇÃO E DESENVOLVIMENTO}

Quadro 2 - Definição das práticas de gestão recursos humanos presentes na empresa

\begin{tabular}{|c|c|c|}
\hline $\begin{array}{c}\text { Práticas de } \\
\text { GRH }\end{array}$ & Funções das práticas de GRH & Trechos das entrevistas que evidenciam resultados \\
\hline $\begin{array}{c}\text { Práticas de } \\
\text { Participação }\end{array}$ & $\begin{array}{l}\text { Procedimentos que orientam a } \\
\text { participação dos colaboradores na } \\
\text { tomada de decisão, resolução de } \\
\text { problemas e nos planos de } \\
\text { desenvolvimento. }\end{array}$ & $\begin{array}{l}\text { "Todas as políticas que eles escrevem nos envolvem pra } \\
\text { discutir, pra dar uma olhada [....], mas de uma forma } \\
\text { geral a gente tá envolvido. E não tem como ser diferente, } \\
\text { porque quem vai operacionalizar é a nossa área". (E14). }\end{array}$ \\
\hline $\begin{array}{l}\text { Práticas de } \\
\text { Relaciona- } \\
\text { mento }\end{array}$ & $\begin{array}{l}\text { Essa prática combina eventos e } \\
\text { ações voltadas à integração e } \\
\text { cooperação no trabalho individual. }\end{array}$ & $\begin{array}{l}\text { "Tudo aqui é feito em equipe }[. . .] \text { senão fosse não } \\
\text { aguentaríamos }[\ldots] \text { não daria certo". (E17). "Não é todo } \\
\text { o grupo que participa o tempo inteiro, mas todos tem } \\
\text { conhecimento do que está acontecendo." (E8). }\end{array}$ \\
\hline $\begin{array}{c}\text { Práticas de } \\
\text { Comunicação }\end{array}$ & $\begin{array}{l}\text { Prioriza a divulgação do que é } \\
\text { considerado prioridade, valorizando } \\
\text { ideias, sugestões e reclamações }\end{array}$ & $\begin{array}{l}\text { "A nossa gestora deixa sempre muito aberto pra gente } \\
\text { questionar o que quer saber." (E16). "A gente usa tudo } \\
\text { o que tem, às vezes é por meio de reunião, às vezes por } \\
\text { meio de e-mail mesmo. Às vezes a gente não tem sala, } \\
\text { mas se é uma coisa que não pode esperar, se reúne ali } \\
\text { mesmo". (E14). }\end{array}$ \\
\hline $\begin{array}{l}\text { Práticas de } \\
\text { Avaliação e } \\
\text { Reconheci- } \\
\text { mento }\end{array}$ & $\begin{array}{l}\text { O objetivo é estimular a avaliação } \\
\text { continuada e reconhecer } \\
\text { desempenhos superiores. }\end{array}$ & $\begin{array}{l}\text { "O feedback formal que eu tive foi através do projeto } \\
\text { Evolução. Já foram duas vezes que eu já passei por essa } \\
\text { avaliação. Também existe a informal o que ocorre nas } \\
\text { reuniões de follow. (E10)" }\end{array}$ \\
\hline $\begin{array}{l}\text { Práticas de } \\
\text { Desenvolvi- } \\
\text { mento }\end{array}$ & $\begin{array}{l}\text { Atividades que devem orientar os } \\
\text { caminhos do desenvolvimento dos } \\
\text { colaboradores, a fim de articular } \\
\text { suas expectativas com as } \\
\text { expectativas estratégicas da } \\
\text { organização. }\end{array}$ & $\begin{array}{l}\text { "Na verdade eu acho que aqui a gente tem muitas } \\
\text { possibilidades de desenvolvimento. Eu vejo as pessoas } \\
\text { sendo encaminhadas pra cursos, eu vejo que no dia-a-dia } \\
\text { a gente consegue se desenvolver bastante, porque os } \\
\text { colegas têm perfis específicos, que são complementares, } \\
\text { então nisso a gente se desenvolve muito." E4. }\end{array}$ \\
\hline
\end{tabular}
Fonte: elaborado pelos autores, 2014.

O segundo eixo deste tópico pretendeu, com base na análise das práticas de GRH levantadas, identificar quais delas podem ser associadas à políticas de gestão em RH capazes de mobilizar processos de interação, compartilhamento e cooperação do trabalho individual. $\mathrm{O}$ princípio que sustenta essa construção defende que as práticas de $\mathrm{RH}$, nas quais forma mobilizados processos de interação, compartilhamento e cooperação apresenta todas as condições de constituir configurações do tipo coletivo, conforme Michaux (2011) e Pauvers e Schieb-Bienfait (2011).

Dentre as 5 práticas de GRH levantadas, identificamos três que apresentam evidências mais nítidas da relação com as políticas mobilizadoras de processos coletivos, a partir da análise dos resultados de entrevistas, cuja síntese é apresentada no quadro 3 a seguir.

Quadro 3: Políticas de Gestão que mobilizam configurações coletivas em práticas RH e evidências

\begin{tabular}{|c|l|l|c|}
\hline $\begin{array}{c}\text { Tipos de Práticas } \\
\text { RH }\end{array}$ & \multicolumn{1}{|c|}{$\begin{array}{c}\text { Políticas de Gestão que } \\
\text { mobilizam configurações } \\
\text { coletivas em práticas RH }\end{array}$} & $\begin{array}{c}\text { Evidências a partir da } \\
\text { análise das entrevistas }\end{array}$ & $\begin{array}{c}\text { Referências } \\
\text { Teóricas }\end{array}$ \\
\hline Participação & $\begin{array}{l}\text { Liderança democrática, autonomia } \\
\text { dos colaboradores e participação } \\
\text { coletiva. }\end{array}$ & $\begin{array}{l}\text { Práticas adotadas no novo projeto } \\
\text { de gestão de pessoas: planos para } \\
\text { realizar ações coletivamente. }\end{array}$ & $\begin{array}{l}\text { Zarifian } \\
(2001) ; \\
\text { Frohm (2002) }\end{array}$ \\
\hline
\end{tabular}

REAd | Porto Alegre - Edição 83 - N 1 - Janeiro/Abril 2016 - p. 252-278 
Francielle Molon da Silva \& Roberto Lima Ruas

\begin{tabular}{|c|c|c|c|}
\hline & & $\begin{array}{l}\text { O novo projeto de Gestão de } \\
\text { Pessoas visa integrar as ações } \\
\text { voltadas ao gerenciamento de } \\
\text { pessoas e está sendo contruído de } \\
\text { maneira coletiva e participativa. } \\
\text { Todos são convidados a contribuir } \\
\text { com ideias, percepções e } \\
\text { experiências e se sentem a vontade } \\
\text { em fazer essa atividade justamente } \\
\text { pelo posicionamento da liderança. }\end{array}$ & \\
\hline Relacionamento & $\begin{array}{l}\text { Integração das pessoas, estímulo às } \\
\text { relações informais e valorização } \\
\text { trabalho em equipe. }\end{array}$ & $\begin{array}{l}\text { Formação de grupos de trabalho } \\
\text { voltados à solução de problemas de } \\
\text { forma coletiva; }\end{array}$ & $\begin{array}{l}\text { Sandberg } \\
(1996)\end{array}$ \\
\hline Comunicação & $\begin{array}{l}\text { Estímulo à comunicação por todos } \\
\text { os meios formais e informais; } \\
\text { comunicação aberta no plano } \\
\text { vertical-hierarquia. }\end{array}$ & $\begin{array}{l}\text { Depoimentos sobre fluxo de } \\
\text { comunicações intensos em } \\
\text { atividades de planejamento e } \\
\text { organização. }\end{array}$ & $\begin{array}{l}\text { Michaux } \\
(2005)\end{array}$ \\
\hline $\begin{array}{c}\text { Avaliação e } \\
\text { Reconhecimento }\end{array}$ & \multicolumn{3}{|c|}{$\begin{array}{l}\text { Não se identificou relação entre políticas de gestão e práticas RH que estimulem } \\
\text { configurações coletivas }\end{array}$} \\
\hline Desenvolvimento & \multicolumn{3}{|c|}{$\begin{array}{l}\text { Não se identificou relação entre políticas de gestão e práticas RH que estimulem } \\
\text { configurações coletivas. }\end{array}$} \\
\hline
\end{tabular}

Fonte: Elaborado pelos autores, 2014.

O terceiro eixo deste tópico destaca as evidências de atributos de competências coletivas nos 3 tipos de Práticas de gestão de RH capazes de mobilizar configurações coletivas. Os atributos de competências coletivas, conforme revisão bibliográfica representam fundamentos do desenvolvimento da configuração coletiva e apresentam formatações do tipo memória coletiva, referenciais comuns, linguagem compartilhada e engajamento subjetivo (RETOUR; KROHMER, 2011). O quadro 4 a seguir sintetiza os resultados dessa análise.

Quadro 4: Atributos de CC nas práticas de Gestão RH e respectivas evidências

\begin{tabular}{|c|c|c|}
\hline $\begin{array}{c}\text { Tipos de Práticas } \\
\text { RH }\end{array}$ & $\begin{array}{l}\text { Atributos de CC } \\
\text { nas Práticas RH }\end{array}$ & $\begin{array}{l}\text { Estratos de depoimentos evidenciando a presença dos } \\
\text { atributos de CC }\end{array}$ \\
\hline \multirow[t]{3}{*}{ Participação } & $\begin{array}{l}\text { Engajamento } \\
\text { Subjetivo: } \\
\text { o novo modelo de } \\
\text { gestão de pessoas } \\
\text { envolve as pessoas da } \\
\text { área. }\end{array}$ & $\begin{array}{l}\text { "A gente não é uma equipe por obrigação, a gente é uma equipe } \\
\text { de gestão de pessoas como um todo, por desejo de ser uma } \\
\text { equipe, por entender que isso fortalece a nossa área. Então o } \\
\text { relacionamento é muito importante, tem que fluir, tem que ser } \\
\text { uma coisa boa". (E1). "Eu acho que a área de gestão de pessoas, } \\
\text { coletivamente faz muito bem o envolvimento, envolver as } \\
\text { entidades do sistema, a relação com as outras entidades, com os } \\
\text { presidentes, com os superintendentes". (E6). }\end{array}$ \\
\hline & $\begin{array}{l}\text { Referenciais Comuns } \\
\text { o envolvimento das } \\
\text { pessoas acaba por } \\
\text { gerar referenciais } \\
\text { comuns. } \\
\text { (SANDBERG,1996) }\end{array}$ & $\begin{array}{l}\text { "A gente sempre é convidado a participar das reuniões e lá a } \\
\text { gente pode opinar, questionar e essa parte é bem tranquilo." } \\
\text { (E16). "O novo modelo de gestão de pessoas vem contribuir e } \\
\text { unificar as políticas, as práticas de gestão de recursos humanos, } \\
\text { enfim, até mesmo doutrinando os gestores, os gerentes." (E18). }\end{array}$ \\
\hline & $\frac{\text { Engajamento }}{\text { Subjetivo: }}$ & $\begin{array}{l}\text { "A gente não é uma equipe por obrigação, a gente é uma equipe } \\
\text { de gestão de pessoas como um todo, por desejo de ser uma } \\
\text { equipe, por entender que isso fortalece a nossa área. Então o }\end{array}$ \\
\hline
\end{tabular}




\section{COMPETÊNCIAS COLETIVAS: CONSIDERAÇÕES ACERCA DE SUA FORMAÇÃO E DESENVOLVIMENTO}

\begin{tabular}{|c|c|c|}
\hline \multirow[t]{2}{*}{ Relacionamento } & $\begin{array}{l}\text { Integração das } \\
\text { pessoas e estímulo às } \\
\text { relaçoes formais e } \\
\text { informais. }\end{array}$ & $\begin{array}{l}\text { relacionamento é muito importante, tem que fluir, tem que ser } \\
\text { uma coisa boa". (E1). "Existe um vínculo, um respeito, ele é } \\
\text { legal, ele é cumprido e vice-versa, ninguém dá o 'pitaco' onde } \\
\text { não deve e as pessoas que estão dentro da área sempre buscam } \\
\text { se ajudar, sempre contribuir, porque uma acaba sendo cliente da } \\
\text { outra".(E11) (RETOUR; KROHMER, 2011) }\end{array}$ \\
\hline & $\begin{array}{l}\frac{\text { Referenciais }}{\text { Comuns: valorizaçao }} \\
\text { trabalho em equipe }\end{array}$ & $\begin{array}{l}\text { "O pessoal mesmo novo, não tem ninguém sozinho, tem sempre } \\
\text { alguém com essa pessoa, mesmo quando ela vai almoçar, vamos } \\
\text { conhecer, vamos no shopping, então é mais a relação na equipe } \\
\text { como um todo". (E14). "[...] na GP as pessoas são solistas, } \\
\text { todas se apoiam ninguém senta em cima da informação". (E2) }\end{array}$ \\
\hline \multirow[t]{2}{*}{ Comunicação } & $\begin{array}{l}\text { Referenciais } \\
\text { Comuns: } \\
\text { fortalecidos pelas } \\
\text { reuniões e pelo } \\
\text { programa de comuni- } \\
\text { caçao o que consoli- } \\
\text { da esses atributos }\end{array}$ & $\begin{array}{l}\text { "Agora a gente tem o programa de comunicação direta que } \\
\text { todas as áreas adotaram, isso pra trazer tudo o que acontece nas } \\
\text { reuniões da diretoria". (E16). "Tem reuniões quinzenais [...], } \\
\text { dessas reuniões de Direx, tu tira uma ATA, com informações } \\
\text { que podem ser compartilhadas e vira um informativo pros } \\
\text { gestores, que tem por obrigação fazer uma reunião com todo o } \\
\text { time e dizer o que aconteceu, o que foi tratado, tirar as dúvidas } \\
\text { que tiverem". (E12). "Existe estímulo a comunicação, é claro. } \\
\text { Ela é transparente, se não tem reunião eles encaminham um } \\
\text { status, se tem reunião eles encaminham uma pauta, encaminham } \\
\text { a apresentação" (E10). }\end{array}$ \\
\hline & $\begin{array}{l}\text { Linguagem } \\
\text { Compartilhada: a } \\
\text { criação de siglas, o } \\
\text { tipo de cooperação de } \\
\text { todos durante as } \\
\text { reuniões. }\end{array}$ & $\begin{array}{l}\text { "Apesar de cada um ter sua caixinha, há interação [...] a gente } \\
\text { tem muita troca porque todo o trabalho é feito muito em } \\
\text { conjunto apesar de cada um ter a sua, o seu objetivo ali, a ideia } \\
\text { é que a gente troque muito dentro da nossa área e todo o } \\
\text { processo". (E8). "Tá começando um trabalho em equipe legal } \\
\text { agora, porque agora (os gestores) começaram a montar um } \\
\text { programa de reuniões" (E3). }\end{array}$ \\
\hline
\end{tabular}

Fonte: elaborado pelos autores, 2014.

\subsection{Identificação das Competências Coletivas da Área de Gestão de Pessoas}

Conforme observamos na revisão bibliográfica, o conceito de competências coletivas pode apresentar uma série de perspectivas conceituais, até mesmo ser qualificado como um termo polissêmico. (MOLON da SILVA, 2012). Assim, ao invés de concentrarmo-nos na tentativa de encontrar exemplos específicos e estáticos de competências coletivas, nossa expectativa foi a de identificar situações nas quais são formados esses construtos, mantendo suas condições de flexibilidade e adequação. Neste sentido, optamos em nossa pesquisa por identificar elementos dinâmicos capazes de compor uma competência coletiva, considerando as noções de CC apontadas por Dejoux (1998), Michaux (2005; 2011), Retour e Krohmer (2006; 2011), Pauvers e Schieb-Bienfait (2011).

O processo que conduziu a análise das informações destacou três elementos capazes de mobilizar e compor uma CC: (i) políticas de gestão que estimulam processos de interação,

REAd | Porto Alegre - Edição 83 - N 1 - Janeiro/Abril 2016 - p. 252-278 


\section{Francielle Molon da Silva \& Roberto Lima Ruas}

compartilhamento e socialização do trabalho; (ii) práticas de GRH capazes de operacionalizar os princípios e políticas voltadas a "socialização" do trabalho gerando configurações coletivas; (iii) os atributos de competências coletivas, que são atributos resultantes da recorrência de atividades de modo coletivo e que acabam por formar e desenvolver competências coletivas.

Empregando essa lógica identificamos a presença de duas competências coletivas no campo investigado. A primeira que consideramos mais consolidada foi denominada competência coletiva Relacionamento e Colaboração. A análise realizada no tópico anterior revelou que as práticas de gestão de $\mathrm{RH}$, na empresa investigada tem estimulado, muito especialmente os atributos Referenciais Comuns e Engajamento Subjetivo A força desses atributos, expressa nos textos de entrevistas apresentados acima, evidencia a presença de uma competência coletiva, neste ambiente, que dinamiza o relacionamento no trabalho e o engajamento em processo de colaboração a fim de alcançar os objetivos da área, o que acaba por estimular um melhor desempenho da área analisada.

A segunda CC identificada é a capacidade de desenvolver soluções conjuntas e trata do desenvolvimento de projetos e programas elaborados em parceria entre a área de $\mathrm{RH}$ e outras áreas da empresa. Essa descoberta é sustentada em evidências retiradas das entrevistas realizadas, das quais apresentamos alguns trechos: "Você é indagado pra trazer novas soluções, mas sempre com apoio [...] nós temos essa parceria, que legal que nós estamos construindo isso juntos" (E7). Ideias complementadas pelo E14 ao afirmar que: "Todas as políticas que eles escrevem eles nos envolvem pra discutir, pra dar uma olhada".

Apesar dessas evidências, constatamos com base no estágio de desenvolvimento dos atributos em cada uma delas, que a competência coletiva capacidade de desenvolver soluções conjuntas, não apresenta o mesmo estágio de consolidação da competência coletiva relacionamento e colaboração.

Finalmente, uma reflexão articulando a análise dos resultados gerais da pesquisa e as categorias de análise associadas à formação de competências coletivas conduziram-nos à construção de um framework acerca desse processo, conforme ilustrado na Figura 1. O framework define condições e relacionamentos envolvendo os seguintes elementos:

a) Fatores Mobilizadores: políticas de gestão que incentivem e reforcem processos de interação e cooperação do trabalho individual no contexto de práticas de gestão de RH;

b) Atributos de Competências Coletivas: resultantes da recorrência e continuidade de processos de interação entre indivíduos, constituindo um coletivo de trabalho consolidado 


\section{COMPETENCIAS COLETIVAS: CONSIDERAÇÕES ACERCA DE SUA FORMAÇÃO E DESENVOLVIMENTO}

e atributos específicos à configurações coletivas, tais como engajamento subjetivo no grupo, memória coletiva, linguagem compartilhada, etc. ;

c) Competências Coletivas - desempenho superior de coletivo de trabalho em função da recorrência de processos de interação e da consolidação de atributos de competência coletiva
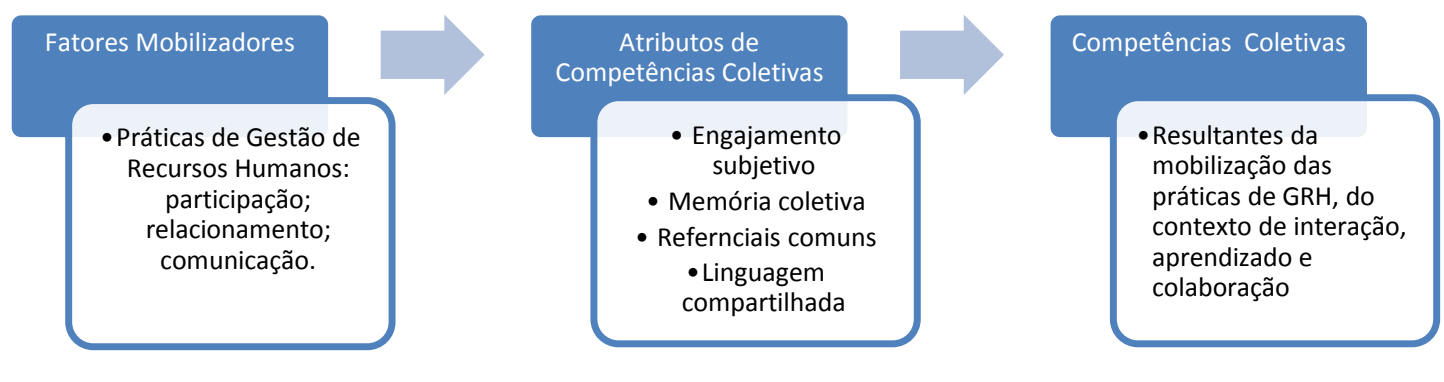

Figura 1 - processo de relacionamento de elementos capazes de estimular o desenvolvimento de competência coletiva. Fonte: elaborado pelos autores, 2014

\section{CONSIDERAÇÕES FINAIS}

O que mobilizou esse trabalho foi o gap entre, de um lado, o discurso teórico destacando a emergência recente dos coletivos de trabalho e o efetivo papel desses coletivos no desempenho das organizações e, de outro, o ambiente organizacional no qual se observa ausência de cultura gerencial e instrumentos adequados para gerir configurações coletivas de trabalho. (MOLON da SILVA, 2013; RUAS et al., 2013; DEFELIX et al. 2014).

Entretanto, pesquisas sobre o tema tem sido um desafio em função exatamente da escassez de trabalhos empíricos sobre a gestão de configurações coletivas de trabalho. Além da limitação gerada pela lacuna na produção científica, o desenvolvimento deste tipo de trabalho é também dificultado pela baixa tangibilidade da noção de coletivos, mesmo no espaço organizacional (COLIN; GRASSER, 2011).

Por outro lado, considerando-se a importância da emergência dessa configuração coletiva no espaço organizacional, também uma consequência do uso crescente de sistemas digitais nesses espaços, é necessário investir nesse conhecimento apesar das limitações e dificuldades. Foi essa a razão que nos mobilizou na direção desta investigação.

Nosso objetivo foi investigar a configuração coletiva, na forma de competências coletivas, a partir de estudo de caso na área de gestão de recursos humanos em empresa 


\section{Francielle Molon da Silva \& Roberto Lima Ruas}

atuando no setor financeiro nacional. Escolhemos o construto competência coletiva como eixo central da pesquisa por entender que sua dinâmica representaria o conjunto de configurações coletivas que o mobilizam e o compõem. A área e as práticas de gestão de recursos humanos em função da proximidade de políticas e princípios de gestão que possam mobilizar a cooperação e interação do trabalho individual, na perspectiva de formar coletivos de trabalho.

Sustentados por uma revisão teórica abrangente, complementada por um diálogo ativo com os profissionais da empresa investigada e com pesquisadores atuando num espaço teórico-empírico similar, foram selecionadas as seguintes categorias de análise: (i) políticas de gestão que estimulam processos de interação e socialização do trabalho; (ii) práticas de GRH capazes de operacionalizar os princípios e políticas voltadas a "socialização" do trabalho gerando configurações coletivas; (iii) atributos de competências coletivas, atributos que fundamentam a formação e desenvolvimento de competências coletivas. A relação entre essas categorias de análise e a dinâmica da formação de competências coletivas originaram um framework que pretende expressar a configuração e a formação e o desenvolvimento de competências coletivas.

Com base nas categorias de análise e neste framework foi possível identificar evidências de atributos de competências coletivas em práticas de gestão de RH, o que também auxiliou na definição da presença de competências coletivas nestas mesmas atividades.

Enfim, a partir da construção teórico-empírica desenvolvida neste artigo foi possível definir elementos que entendemos nós, podem constituir referências preliminares para tratar da gestão de coletivos no espaço organizacional, o que nos pareceu a grande contribuição deste trabalho. Esperamos que essa construção, guardada a necessidade de uma adaptação importante a outros ambientes e situações, possa ser empregada em outros estudos semelhantes e servir como objeto de confirmações e críticas.

Certamente uma das limitações principais desta pesquisa dizem respeito a profunda associação dos resultados obtidos com o tipo de organização e área nas quais foi realizada a pesquisa. Essa condição reforça a necessidade de adaptação o que deve gerar a descoberta de outros tipos de fatores mobilizadores, de práticas de gestão, assim como outros tipos de atributos de Competências Coletivas. Entretanto, o que defendemos como contribuição mais importante do trabalho é a preservação das categorias de análise para tratar de configurações coletivas. 


\section{COMPETÊNCIAS COLETIVAS: CONSIDERAÇÕES ACERCA DE SUA FORMAÇÃO E DESENVOLVIMENTO}

\section{REFERÊNCIAS}

BARDIN, L. Análise de conteúdo. Tradução de L. A. Reto \& A. Pinheiro. Lisboa: Edições 70, 2002.

BARNEY, J. B. Firm resourced and sustained competitive advantage. In: Journal of Management, v. 7, n. 1, p. 99-120, 1991.

BATAILLE, F. Competence collective et performance. Revue de Gestion des Ressources Humaines. Avril, mai, juin 2001, p. 66-81.

BITENCOURT, C. Gestão contemporânea de pessoas: novas práticas, conceitos tradicionais. Porto Alegre: Bookman, 2004.

BONOTTO, F.; BITENCOURT, C. C. The Collective Competences: a way to inspire the expansive learning. In: Seventh International Conference on HRD Research and Practice Across Europe. Tillburg, 2006.

BONOTO, F.; KLEIN, M. F. Competência Coletiva. In: BITENCOURT, C. e col. Gestão Contemporânea de Pessoas: novas práticas, conceitos tradicionais. $2^{\mathrm{a}}$ Ed. Porto Alegre: Bookman, p. 01-09, 2010.

BRANDÃO, H. P.; GUIMARÃES, T.A. Gestão de competências e gestão de desempenho. Revista RAE, FGV,v.41, n.1, jan./mar. 2001.

COLIN, T.; GRASSER, B. Das competências individuais à competência coletiva: contribuições da aprendizagem em um serviço de emergência hospitalar. In: RETOUR, D. et al. Competências Coletivas: no limiar da estratégia. Porto Alegre: Editora Bookman, p. 7998, 2011.

COMINI, G. M.; FERNANDES, B. H. R. . Limitações na Estruturação de Modelos de Gestão por Competências: Uma Análise de Organizações Líderes em diversos Setores. In: XXXII ENANPAD 2008 Encontro científico de Administração - 6 a 10/09/, 2008, Rio de Janeiro. XXXII ENANPAD 2008. Rio de Janeiro, 2008.

DEFELIX, C.; LE BOULAIRE, M.; MONTIES, V.; PICQ, T. La compétence collective dans le contexte de la globalisation du management: retrouver le lien avec la performance..

http://www.cairn.info/article_p.php?ID_ARTICLE=GRH_142 0031. Acesso em janeiro 2015.

DEJOUX, C. Pour une approche transversale de la gestion des competences. Gestion 2000. Nov-dec 1998, p. 15-38 
DEMO, G.; NUNES, I. Política de Gestão de Pessoas: pressupostos, definições, resultados e produção internacional recente. In: DEMO, G. (org.). Políticas de Gestão de Pessoas nas Organizações: estudo da arte, produção nacional, agenda de pesquisa, medidas e estudos relacionais. São Paulo: Atlas, p. 33-48, 2012.

DIAS, G. B. et al. Revisando a noção de competências na produção cientifica em administração: avanços e limites. In: DUTRA, J. S.; FLEURY, M. T. L.; RUAS, R. L. (org.) Competências: conceitos, métodos e experiências. São Paulo: Atlas, 2008.

DUBOIS, M.; RETOUR, D. La competence collective : validation empirique fondées sur les représentations operatoires de travail partagées. Psychologie du Travail et des

Organisations, 5 (2-1), p. 225-243, 1999.

FRANCO. M. L. P. B. Análise de Conteúdo. 2. Ed. Brasília: Líber Livro Editora, 2005.

FROHM, C. Collective competence in an interdisciplinary project context. Sweden: UniTryck, 2002.

GOETZ, J. P.; LECOMPTE, M. D. Etnografía y diseño cualitativo en investigación educativa. Madrid: Ediciones Morata, 1988.

GRANT, R. M., The Resource-Based Theory of Competitive Advantage: Implication for strategy Formulation. California Management Review, [S.I.: s.n.]: v. 33, n.3, p.114-135, 1991

GRIMAND, A. Das competências individuais às competências estratégicas: Uma experiência de modelagem das estratégias concorrenciais com base na gestão de recursos humanos. In:

RETOUR, D. et al. Competências Coletivas: no limiar da estratégia. Porto Alegre: Bookman, p. 23-44, 2011.

HANSSON, J. Total QualityManagement - aspects of implementation and performance. Investigations with a focus on small organizatios. 2003. Doctoral Thesis. Department of Business Administration and Social Science. Disponível em: http://pure.ltu.se/portal/files/152259/LTU-DT-0307-SE.pdf. Acesso março de 2011.

HEENE, A.; SANCHEZ, R. Competence based strategic management. Chichester: John Wiley \& Sons, 1997. 


\section{COMPETENCIAS COLETIVAS: CONSIDERAÇÕES ACERCA DE SUA FORMAÇÃO E DESENVOLVIMENTO}

HELFAT, C.E.; PETERAF, M.A.The dynamic Resource-Based View: Capability Lifecycles. Strategic Management Journal, p. 997-1010, 2003.

JAVIDAN, M. Core competence: what does it mean in practice? Long Range Planning, [S.I.]: v. 31, $\mathrm{n}^{\circ} 1,1998$.

KING, A. W.; FOWLER, S. W.; ZEITHAMI, C. Competências organizacionais e vantagem competitiva: o desafio da gerência intermediária. RAE, [S.I.: s.n.]: v.42, n. 1, jan./mar. 2002.

LAVILLE, C.; DIONNE, J. A construção do saber: manual de metodologia de pesquisa em ciências humanas. Porto Alegre: Artes Médicas, 1999.

LE BOTERF, G. De La competénce. Paris: Les Editions d'Organization, 1995.

De quelle concept de compétence avons-nous besoin? In: Soin Cadres,

fev./2002. Disponível em: http://www.guyleboterf-conseil.com/images/Soins\%20cadres.PDF. Acesso em agosto de 2012.

LE BOULAIRE, M. DEFELIX; GAUTIER, B.; PICQ, T. Performance: Retrouver les Chemins du Collectif? Disponível em http://www.entreprise-personnel.com/fr/publications/etudendeg315. Acesso em outubro de 2014.

LJUNGQUIST, U. (2007). Core competency beyond identification: presentation of a model. Management Decision, 45 (3), 393 - 402.

MASCARENHAS, A. O. Gestão estratégica de pessoas: evolução, teoria e crítica. São Paulo: Cencage Learning, 2008.

MICHAUX, V. Compétences collectives et haute performance: apports thóriques et enjeux opérationnels. In: Revue de Gestion des Ressources Humaines, v. 58, p. 45-66, Oct./Dec. 2005.

Articular as competências individual, coletiva, organizacional e estratégica: esclarecendo a teoria dos recursos e do capital social. In: RETOUR, D. et al. Competências Coletivas: no limiar da estratégia. Porto Alegre: Bookman, p. 01-22, 2011.

MILLS,J.; PLATTS,K.; BOURNE,M.; RICHARD,H. Competing through competences. Cambridge: University Press, 2002 
MIRANDA, K. F. ; GALLON, A. V. ; DE LUCA, M. M. M. ; CABRAL, J. E. O. . A capacidade inovativa e o desempenho econômico-financeiro de empresas inovadoras brasileiras. REAd. Revista Eletrônica de Administração (Porto Alegre. Online), v. 81, p. 269299,2015

MOLON DA SILVA, F. O que sabemos sobre competências coletivas? In: XXXVI Encontro da Associação Nacional de Pós-Graduação e Pesquisa em Administração, 2012, Rio de Janeiro: Anais Eletrônicos, 2012.

As práticas de gestão de recursos humanos e o processo de identificação de competências coletivas: um estudo de caso na área de gestão de pessoas do Centro Administrativo do Sicredi. 29 de maio de 2013. 193 f. Tese de Doutorado. Universidade Federal do Rio Grande do Sul - Programa de Pós-Graduação em Administração. Porto Alegre, 2013.

NELSON, R; WINTER, S. An evolutionary theory of economic change. Cambridge: Harward University Press, 1982.

NORDHAUG, O.; GRÖNHAUG, K. Competences as resources in firm. In: International Journal Resources Management, v. 5, n.1, p. 89, 1994.

NUNES, J. O. C. ; OLIVEIRA, H. V. . Novas Tendências da Área de Recursos Humanos das Organizações: Sob os Enfoques Explicativos das Perspectivas Estrutural e Estratégica de Mudanças. REAd. Revista Eletrônica de Administração, v. 03, p. 397-421, 2010.

PAUVERS, B.; SCHIEB-BIENFAIT, N. Competências individuais e coletivas no centro da estratégia: um estudo de caso longitudinal em uma empresa cooperativa de construção civil In: RETOUR, D. PICQ, T.; DEFÉLIX, C. ;RUAS, R. Competências Coletivas: no limiar da estratégia. Porto Alegre: Bookman, p. 127-152, 2011.

PRAHALAD, C.K.; HAMEL, G. The Core Competence of the Corporation. Harvard Business Review. [S.I.: s.n.]: v.90, n.3, p. 79-93, May/June, 1990.

RETOUR, D.; KROHMER, C. A La Competence collective maillon clé de la gestion des competences. DEFELIX,C. ; KLASFERD,A. ; OIRY, E. Nouveaux regards sur la gestion des competences. Paris, AGH-Vuibert, 2006. 


\section{COMPETÊNCIAS COLETIVAS: CONSIDERAÇÕES ACERCA DE SUA FORMAÇÃO E DESENVOLVIMENTO}

- A competência coletiva: uma relação-chave na gestão das competências. In:

RETOUR, D. PICQ, T.; DEFÉLIX, C. ;RUAS, R.. Competências Coletivas: no limiar da estratégia. Porto Alegre: Bookman, p. 45-78, 2011.

RETOUR, D.; PICQ, T.; DEFÉLIX, C. Gestion des compétences, nouvelles relations, nouvelles dimensions. Paris: Vuibert, 2009

ROSA, J. S.; BITENCOURT, C. A Dinâmica das Competências Coletivas em um Contexto de Redes de Cooperação. In: UNOPAR Científica. Ciências Jurídicas e Empresariais, v. 11, p. 5-14, 2010.

RUAS, R.L. Desenvolvimento de Competências Gerenciais e a Contribuição da Aprendizagem Organizacional.in FLEURY, MT;OLIVEIRA, MM, Gestão Estratégica do Conhecimento. São Paulo, Atlas, 2001.

Gestão por competências: uma contribuição à estratégia das organizações. RUAS, R. L.; Antonello, C.; BOFF, L. H. Os novos horizontes da gestão: aprendizagem organizacional e competências. Porto Alegre: Bookman, 2005.

RUAS, R.; MOLON DA SILVA, L.; BECKER, G.V; COMINI, G. Competências Coletivas: Resultados Teórico-Práticos acerca de sua configuração em Empresas Brasileiras. XXXVII ENANPAD, 2013.

SANCHEZ, R.; HEENE, A. The New Strategic Management. Organization, Competition and Competence. New York: John Wiley and Sons, 2004.

SANDBERG, J. Human competence at work. Suécia: Grafikerna I Kungälv, 1996.

SANDBERG, J.; TARGAMA, A. Managing Understanding in Organizations. London: Sage, 2006.

STALK, G.; EVANS, P.; SCHULMAN, E.; "Competing on Capabilities: The New Rules of Corporate Strategy”, Harvard Business Review, v.70, n.2, p. 57-69, 1992.

TRIVIÑOS, A. N. S. Introdução à pesquisa em ciências sociais: a pesquisa qualitativa em educação. São Paulo: Atlas, 1987. 
Francielle Molon da Silva \& Roberto Lima Ruas

ULRICH, D.; BEATTY, D. From Partners to Players: Extending the HR Playing Field. In: Human Resource Management, n. 40, v. 4, p. 293-307, 2001.

WARNIER, V. Construire Les Compétences Stratégiques - Le Cas De L'industrie De La Dentelle Haut De Gamme. Paris : Vuibert, 2008

WERNERFELT, B. A Resource-based View of the Firm. In: Strategic Management Journal, v. 5, p. 171-180, 1984.

YIN, R. K. Estudo de caso: planejamento e métodos. (2Ed.). Porto Alegre: Bookman, 2001.

ZARIFIAN, P. Objetivo competência: por uma nova lógica. São Paulo: Atlas, 2001. 